\title{
Finnish nurses' attitudes towards their role in the euthanasia process
}

\section{Anja Terkamo-Moisio}

University of Eastern Finland, Finland

\section{Chris Gastmans}

Catholic University of Leuven, Belgium

\section{Olli-Pekka Ryynänen}

University of Eastern Finland, Finland; Kuopio University Hospital, Finland

\section{Anna-Maija Pietilä}

University of Eastern Finland, Finland; Kuopio Social and Health Care Services, Finland

\begin{abstract}
Background: Nurses' voices remain unheard in most debates about euthanasia, although their crucial role in the euthanasia process is widely acknowledged. Moreover, in Canadian euthanasia law, nurses have a more active role, which further highlights the need for knowledge about nurses' attitudes towards their role in the euthanasia process.

Research questions: What are Finnish nurses' attitudes towards their potential role in the euthanasia process? Which characteristics are associated with those attitudes?

Research design: Cross-sectional web-based survey.

Participants and research context: 1003 nurses, recruited via social media and the members' bulletin of the Finnish Nurses Association.

Ethical considerations: Ethical approval was obtained from the Committee on Research Ethics of the university to which the first author was affiliated.

Findings: The great majority (85.2\%) of nurses felt that their perspective should be considered in decisionmaking related to euthanasia. Furthermore, most of the participants (74.7\%) reported willingness to participate in the euthanasia process if it were legal, and $88.6 \%$ agreed that a nurse should be present when euthanasia is performed if the patient wishes so. Furthermore, over half agreed that some of the preparatory tasks were part of their job description. However, a minority (32.9\%) agreed with a possible obligation to participate based on their profession. Nurses' age, religiosity and educational level influenced their attitudes in the current results.

Discussion: Despite the strong agreement on decision-making concerning euthanasia and participation in the euthanasia process, obligation to participate based on the profession was rejected by most participants. Nurses regarded themselves as consultants in the decision-making process, which may indicate their unwillingness to share the responsibility for the decision itself.
\end{abstract}

Corresponding author: Anja Terkamo-Moisio, Department of Nursing Science, University of Eastern Finland, PO Box I627, 702 I I Kuopio, Finland.

Email: anja.terkamo-moisio@uef.fi 
Conclusion: Specific safety mechanisms should be considered to protect nurses who refuse to be involved in the euthanasia process due to harm that involuntary participation might cause.

\section{Keywords}

Attitude, ethics, euthanasia, Finland, nursing, social media, web-based survey

\section{Introduction}

Euthanasia is defined as 'intentionally terminating life by another person than the person concerned, at this person's request'. 'This definition is used in the euthanasia legislation of the Netherlands, Belgium and Luxembourg. According to this definition, the euthanasia request must be voluntary and explicit, thus excluding any involuntary and non-voluntary cases. ${ }^{1,2}$ In 2017 , euthanasia is legal in the Netherlands, Belgium, Luxembourg, Colombia and Canada. ${ }^{1,2}$ For the first time, the legislation in Canada regards nurse practitioners as potential performers of euthanasia, ${ }^{3,4}$ which sets the legislation apart from all other euthanasia laws, according to which euthanasia is to be performed by a physician. ${ }^{1,2}$ This new role of nurses in Canadian euthanasia law will influence future debate on euthanasia and nurses' role in the euthanasia process also in other countries where the topic is discussed. In Finland, for instance, a citizens' initiative that promotes the legalisation of euthanasia has received over 63,000 statements of support by January $2017,{ }^{5}$ as a result of which the Finnish parliament is expected to take a stand on euthanasia and its legalisation in $2017 .^{6}$

\section{Background}

\section{Nurses' role in the euthanasia process}

The significant role of nurses in the euthanasia process is widely recognised and described in previous literature from Belgium and the Netherlands, countries with the longest experience in euthanasia. ${ }^{7-13}$ The euthanasia process starts with the patient's request for euthanasia. A nurse is often the first person to whom a patient expresses the euthanasia request. ${ }^{9}$ This may be attributed to the nurses' continuous presence and the confidential relationship that nurses have with their patients. ${ }^{7,9}$ After receiving the patient's request, the nurse initiates an interpretative dialogue with the patient, trying to understand the reasons underlying his or her wish for euthanasia. It has been noted that actively listening to the patient is a crucial component of this communication. ${ }^{7,10}$ Furthermore, nurses provide euthanasia-related information to patients and their relatives. They also relay the patient's request to the physician and other members of the care team. ${ }^{7,11}$

Nurses' involvement in the decision-making differs in Belgium and the Netherlands. In Belgium, the consultation of the nursing team directly involved in the euthanasia process is laid down in the euthanasia law, whereas in the Netherlands, nurses' role in decision-making is not regulated in the law. ${ }^{1,8,9,12}$ However, nurses' involvement in the decision-making has been regarded as essential due to the information that they may provide about the patient. ${ }^{7,8,13}$ Moreover, nurses may feel unable to carry out their responsibility to ensure that the patient's request is understood accurately if they are excluded from the decision-making. ${ }^{7,8}$

At the moment, when euthanasia is carried out, the primary role of nurses, if they are present, consists of providing support to the patient and his or her relatives. ${ }^{7,9}$ Preparatory activities, such as inserting an infusion cannula or preparation of euthanatics, are not regarded as part of the professional responsibilities of nurses. ${ }^{8,13}$ However, these tasks are sometimes carried out by nurses and justified, for example, if the physician responsible for performing euthanasia is inexperienced. ${ }^{9}$ 


\section{Nurses' attitudes towards their role in the euthanasia process}

Nurses' attitudes towards euthanasia and its legalisation have been reported in an abundance of previous literature. ${ }^{14-19}$ However, little is known about nurses' attitudes towards their own role in the euthanasia process as well as on their willingness to participate in the process or even perform euthanasia in general. .,15,20 $^{\text {The }}$

The role of nurses in the euthanasia process is much broader than the preparedness or willingness to perform euthanasia previously described and presented in literature. ${ }^{4,7}$ However, in previous studies, nurses' role has often been reduced to comprise only of the performance of euthanasia. For example, during the current millennium, five studies have addressed nurses' willingness to perform euthanasia. ${ }^{16,18,21-23}$ Based on the results, $10 \%-17 \%$ of the nurses noted in general that they would be willing to perform euthanasia if it were legal. ${ }^{16,21-23}$ An exception was the study of Tamayo-Velazquez et al., ${ }^{18}$ where it was found that $54 \%$ of the participating nurses had a predisposition towards carrying out euthanasia if would be legalised.

In the euthanasia process, nurses enter into a highly interpersonal relationship with their patients that involve deeply rooted core values of both parties. ${ }^{4}$ This relationship is described as emotionally demanding by the nurses, which means that involuntary participation in euthanasia process is regarded as traumatising. ${ }^{4,24}$ In accordance with the existing euthanasia laws ${ }^{1}$ and the current position statement of the International Association for Hospice and Palliative Care (IAHPC), ${ }^{25}$ nurses have regarded their right to a conscious objection as one of the most important prerequisites of the legalisation of euthanasia. ${ }^{24}$

It has been argued that despite their crucial role in the euthanasia process, nurses are overlooked in most debates about euthanasia. ${ }^{4}$ They should, however, be closely involved in the ongoing discussions about euthanasia due to the care that they provide for dying patients as well as their more active role specified in the euthanasia law in Canada. ${ }^{2-4,7}$ Hence, the aim of this study was to describe nurses' attitudes towards their role in the euthanasia process in Finland. An additional aim of this study was to analyse the factors that influence these attitudes and reveal possible connections between nurses' attitudes towards euthanasia and their role in the euthanasia process.

\section{Methods}

\section{Instruments}

Due to the lack of a comprehensive measurement instrument, a new electronic questionnaire was developed for this study. The used questionnaire included five components: (1) demographic characteristics, (2) workrelated characteristics, (3) the Centrality of Religion Scale (CRS), (4) nurses' euthanasia-related attitudes and (5) nurses' attitudes towards their role in a euthanasia process.

Demographic characteristics consisted of the participant's age, gender, marital status, most recent level of education and his or her religious affiliation. Nurses were further asked to state if they had children and the region of their primary residence.

The work-related questions included nurses' shift patterns (two-shift/three-shift work, day-time/nighttime work, etc.) and their working environment (primary/secondary or tertiary care, elderly care etc.). Further questions were concerned with the nurses' work experience and the most typical patient for whom they provide care. In addition, nurses were asked to assess their expertise in pain management and end-oflife (EoL) care with a four-step scale ('very poor' to 'very good'). They were also asked to report how often they encountered dying or dead patients.

The CRS, described in detail by Huber and Huber, ${ }^{26}$ was employed to measure participants' religiosity. This internationally validated scale measures religiosity in five core dimensions (intellect, ideology, public 
practice, private practice and experience) based on the multidimensional model of religion of Stark and Glock. The longest version of the CRS was chosen in this study due to the strong evidence of its reliability and validity. ${ }^{26}$ The first author translated the CRS from English to Finnish and discussed it in an expert panel. Subsequently, the CRS was translated back from Finnish to English by an authorised translator and then compared with the original.

Nurses' euthanasia-related attitudes were assessed by 13 statements. The statements are described and the results reported in more detail elsewhere. ${ }^{14}$ The final section of the questionnaire was concerned with nurses' attitudes towards their role in the euthanasia process. It consisted of eight statements based on the existing literature ${ }^{7,9,11}$ and a previously conducted qualitative study. ${ }^{24}$ These statements were designed and discussed among experts representing nursing science, medicine and theology. The participating nurses were asked to state their agreement with individual statements on a 5-point Likert-type scale ('Strongly disagree' to 'Strongly agree'). To avoid ambiguity, euthanasia was clearly defined as 'a deliberate act to terminate another person's life at his/her explicit request' before the statements. ${ }^{27,28}$

To ensure the reliability and repeatability of the questionnaire, a test-retest study was conducted with 19 respondents prior to the data collection. In addition, a preliminary pilot study was conducted among 91 nursing students to ensure the feasibility of the designed questionnaire. No changes were made to the questionnaire based on the results of these tests. The data of the pilot study were excluded from this study.

\section{Data collection}

The inclusion criteria of this study were being a nurse, sufficient skills in the Finnish language and minimum age of 18 years. The data were collected online over a 4-week period during October-November 2014. In Finland, there are over $100,000^{29}$ qualified nurses, nearly half of whom belong to the Finnish Nurses Association. ${ }^{30}$ In October 2014, information about the study was provided to the nurses in the members' bulletin of the Finnish Nurses Association, which had a circulation of 29,484. In addition, social media was employed as further recruitment channel in this study. Information about the study was published in the first author's public blog, seven discussion boards, Facebook, and Twitter. Despite the fact that social media is a rather uncommon method of recruitment in health and nursing science, it enables accessing a large population in geographically diverse areas. ${ }^{31,32}$ Moreover, it offers a possibility to reach individuals

who are difficult to reach with traditional methods, which strengthens the generalisability of the results, ${ }^{31-33}$ although the response rate may not be calculated as in this study.

\section{Ethical considerations}

Ethical approval (5/2014) was obtained for this study from the Committee on Research Ethics of the university to which the first author was affiliated. S. Huber, the developer of the CRS, granted permission for the use of the scale in this study. Nurses gave their informed consent by submitting the completed questionnaire, which also included information about the study. ${ }^{34}$ The research topic was considered sensitive, especially when nurses were asked about their attitudes towards participation in an act that is currently illegal; therefore, the emphasis was set on the voluntariness of the participation and anonymity of the participants. Both were supported by the chosen recruitment and data collection strategies, which followed the recommendations of the ethical decision-making of the Association of Internet Researchers where applicable. ${ }^{35}$ Nurses were able to complete the questionnaire wherever and whenever they chose, which strengthened voluntariness and anonymity. In addition, this might have reduced the tendency of the nurses to give answers that they considered to be commonly accepted, which increased the authenticity of their answers. ${ }^{31,33}$ 


\section{Data analysis}

Prior to the data analysis, which was conducted with SPSS 21 for Windows, 26 records were moved based on missing information, including eight or more missing responses at the individual level. Thus, the cut-off point was $28.5 \%$.

The variables for the most recent level of education were recoded into six categories based on the International Standard Classification of Education (ISCED), 2011. In addition, the initially fivecategory variables for nurses' attitudes towards their role in a euthanasia process were recoded into three categories (Disagree-Cannot say-Agree). Nurses were further categorised into three groups: non-religious, religious and highly religious based on the aggregate of CRS, which was computed deductively for each participant. ${ }^{26}$

The relationship between nurses' attitudes towards their role in a euthanasia process and the independent variables was investigated with chi-square test $\left(\chi^{2}\right) .{ }^{36}$ Pearson's correlation was used to examine the connections between nurses' attitudes towards their role in a euthanasia process and their attitudes towards euthanasia. Statistical significance was indicated by $p$-values of $<0.05$. $^{36}$

\section{Results}

\section{Nurses' demographic and work-related characteristics}

A total of 1003 nurses, aged 20-73 years, participated in this study. The mean age of the participating nurses was 39.54 (standard deviation $(\mathrm{SD})=11.88$ ) years and most of them $(93.0 \%)$ were female (Table 1). Nurses' primary places of residence were located in all 19 regions of Finland, and, in addition, six of the participants had their primary residence abroad. The majority (50.8\%) of the nurses were religious, most of them Lutheran (71.0\%). Nurses' average work experience was $13.16(\mathrm{SD}=10.6)$ years, ranging from 0 to 52 years (Table 1). Most participants encountered dying patients monthly or less frequently, worked mainly $(38.1 \%)$ in secondary or tertiary healthcare, and assessed their expertise in pain management and EoL care as good (Table 2).

\section{Nurses' attitudes towards their role in a euthanasia process}

The majority of participated nurses $(85.2 \%)$ considered that nurses' perception should be taken into consideration in the decision-making concerning euthanasia and $73.7 \%$ of them agreed with nurses' active participation in euthanasia-related decision-making (Table 3). Preparation of the patient for the euthanasia procedure was seen as part of their job description by most (72\%) of the nurses. Furthermore, over half of the respondents $(61.4 \%)$ agreed with the handling of euthanatics (for example diluting) or inserting an infusion cannula $(69.2 \%)$ as part of their profession (Table 3). The great majority $(88.6 \%)$ of the nurses agreed with the statement that nurses should be present when euthanasia is carried out if the patient wishes so. By contrast, a minority $(32.9 \%)$ of the respondents agreed that nurses could be obliged to participate in the euthanasia process based on the profession. However, $74.7 \%$ of the nurses would be prepared to personally participate in the euthanasia process if it were legal (Table 3 ).

\section{Factors influencing nurses' attitudes towards their role in the euthanasia process}

The results of the chi-square test revealed that participants who were 40 years or older disagreed more often with nurses' active participation in decision-making than the younger nurses (Table 4). By contrast, agreement with taking nurses' perceptions into account in the euthanasia-related decision-making was not influenced by any factors included in this study. Older nurses were less likely to agree with the handling of 
Table I. Nurses' demographic characteristics.

\begin{tabular}{|c|c|c|}
\hline & $f$ & $\%$ \\
\hline \multicolumn{3}{|l|}{ Age group $(n=1003)$, years } \\
\hline $20-29$ & 266 & 26.5 \\
\hline $30-39$ & 256 & 25.5 \\
\hline $40-49$ & 240 & 23.9 \\
\hline $50-59$ & 187 & 18.6 \\
\hline $60-69$ & 52 & 5.2 \\
\hline 70 or above & 2 & 0.2 \\
\hline \multicolumn{3}{|l|}{ Gender $(n=1003)$} \\
\hline Male & 66 & 6.6 \\
\hline Female & 933 & 93.0 \\
\hline Do not want to state & 4 & 0.4 \\
\hline \multicolumn{3}{|l|}{ Marital status $(\mathrm{n}=1000)$} \\
\hline Single & 152 & 15.2 \\
\hline Relationship & 67 & 6.7 \\
\hline Cohabitation/marriage & 676 & 67.4 \\
\hline Divorced & 95 & 9.5 \\
\hline Widow & 10 & 1.0 \\
\hline \multicolumn{3}{|c|}{ Parental status (i.e. having children? $\mathrm{n}=995$ ) } \\
\hline No & 368 & 36.7 \\
\hline Yes & 627 & 62.5 \\
\hline \multicolumn{3}{|l|}{ Latest education $(\mathrm{n}=999)$} \\
\hline Lower secondary education & 13 & 1.3 \\
\hline Upper secondary education & 8 & 0.8 \\
\hline Short-cycle tertiary education & 227 & 22.7 \\
\hline Bachelor or equivalent level & 614 & 61.5 \\
\hline Master or equivalent level & 133 & 13.3 \\
\hline Doctoral or equivalent level & 4 & 0.4 \\
\hline \multicolumn{3}{|l|}{ Religion $(\mathrm{n}=998)$} \\
\hline Buddhism & 3 & 0.3 \\
\hline Islam & I & 0.1 \\
\hline Lutheran & 712 & 71.0 \\
\hline No religion & 231 & 23.0 \\
\hline Orthodox & 10 & 1.0 \\
\hline Other & 39 & 3.9 \\
\hline Roman Catholicism & 2 & 0.2 \\
\hline \multicolumn{3}{|l|}{ Religiosity $(\mathrm{n}=1003)$} \\
\hline Non-religious & 424 & 42.3 \\
\hline Religious & 510 & 50.8 \\
\hline Highly religious & 69 & 6.9 \\
\hline
\end{tabular}

euthanatics, insertion of I.V. cannula or preparing the patient for the euthanasia procedure as part of their job description than the younger participants. Furthermore, according to their responses, nurses who were at least 40 years would be less prepared than their younger colleagues to participate in the euthanasia process if it were legal (Table 4).

Agreement with nurses' active involvement in the decision-making process concerning euthanasia was greater among those nurses who were not married or cohabiting. These nurses also reported greater agreement with the handling of euthanatics, insertion of I.V. cannula and preparing the patient for the euthanasia procedure than did the participants who were married or cohabiting (Table 4). Married or 
Table 2. Nurses' work-related characteristics.

\begin{tabular}{|c|c|c|}
\hline & $f$ & $\%$ \\
\hline \multicolumn{3}{|l|}{ Work experience $(n=992)$, years } \\
\hline $0-9$ & 449 & 44.8 \\
\hline $10-19$ & 265 & 26.4 \\
\hline $20-29$ & 164 & 16.4 \\
\hline $30-39$ & 99 & 9.9 \\
\hline 40 or above & 15 & 1.5 \\
\hline \multicolumn{3}{|l|}{ Work place $(\mathrm{n}=1002)$} \\
\hline Not working as a nurse & 78 & 7.8 \\
\hline Secondary or tertiary healthcare & 382 & 38.1 \\
\hline Deputising for a nurse in different units & 79 & 7.9 \\
\hline In a primary care hospital & 118 & 11.8 \\
\hline In a healthcare centre & 28 & 2.8 \\
\hline In a institution for elderly persons & 96 & 9.6 \\
\hline In a private sector & 77 & 7.7 \\
\hline Other & 144 & 14.4 \\
\hline \multicolumn{3}{|l|}{ Working hours $(\mathrm{n}=992)$} \\
\hline Regular daytime job & 235 & 23.4 \\
\hline Regular night work & 17 & 1.7 \\
\hline Two-shift work & 193 & 19.2 \\
\hline Three-shift work & 468 & 46.7 \\
\hline I do not work as a nurse & 79 & 7.9 \\
\hline \multicolumn{3}{|l|}{ Common patient $(\mathrm{n}=936)$} \\
\hline Child or adolescence & 52 & 5.2 \\
\hline Working age & 325 & 32.4 \\
\hline Eldery person & 559 & 55.7 \\
\hline \multicolumn{3}{|l|}{ Encounter dying patients $(n=990)$} \\
\hline Daily & 72 & 7.2 \\
\hline Weekly & 154 & 15.4 \\
\hline Monthly & 300 & 29.9 \\
\hline Less than monthly & 305 & 30.4 \\
\hline Never & 159 & 15.9 \\
\hline \multicolumn{3}{|l|}{ Encounter death patients $(\mathrm{n}=98 \mathrm{I})$} \\
\hline Daily & 5 & 0.5 \\
\hline Weekly & 56 & 5.6 \\
\hline Monthly & 221 & 22.0 \\
\hline Less than monthly & 428 & 42.7 \\
\hline Never & $27 \mid$ & 27.0 \\
\hline \multicolumn{3}{|l|}{ Expertise in pain management $(n=990)$} \\
\hline Very good & 98 & 9.8 \\
\hline Good & 657 & 65.5 \\
\hline Cannot say & 152 & 15.2 \\
\hline Weak & 76 & 7.6 \\
\hline Very weak & 7 & 0.7 \\
\hline \multicolumn{3}{|l|}{ Expertise in end-of-life care $(n=991)$} \\
\hline Very good & 86 & 8.6 \\
\hline Good & 586 & 58.4 \\
\hline Cannot say & 199 & 19.8 \\
\hline Weak & 112 & 11.2 \\
\hline Very weak & 8 & 0.8 \\
\hline
\end{tabular}


Table 3. Nurses' attitudes towards their role in a euthanasia process.

\begin{tabular}{|c|c|c|c|c|c|c|}
\hline \multirow[b]{2}{*}{ Statement } & \multicolumn{2}{|c|}{ Disagree } & \multicolumn{2}{|c|}{ Cannot say } & \multicolumn{2}{|c|}{ Agree } \\
\hline & $f$ & $\%$ & $f$ & $\%$ & $f$ & $\%$ \\
\hline $\begin{array}{l}\text { I. Nurses should be actively involved in the decision-making process concerning } \\
\text { euthanasia. }\end{array}$ & 175 & 17.4 & 89 & 8.9 & 739 & 73.7 \\
\hline $\begin{array}{l}\text { 2. Nurses' perspective should be taken into account in the decision-making process } \\
\text { concerning euthanasia. }\end{array}$ & 92 & 9.2 & 56 & 5.6 & 854 & 85.2 \\
\hline 3. Handling of euthanatics (e.g. dilution) is part of nurses' job description. & 265 & 26.4 & 122 & 12.2 & 616 & 61.4 \\
\hline $\begin{array}{l}\text { 4. Preparing the patient for the euthanasia procedure is part of nurses' job } \\
\text { description. }\end{array}$ & 185 & 18.5 & 95 & 9.5 & 720 & 72.0 \\
\hline $\begin{array}{l}\text { 5. Insertion of I.V. cannula for the euthanasia procedure is part of nurses' job } \\
\text { description. }\end{array}$ & 212 & 21.1 & 97 & 9.7 & 694 & 69.2 \\
\hline $\begin{array}{l}\text { 6. A nurse should be present during the euthanasia procedure if the patient so } \\
\text { wishes. }\end{array}$ & 88 & 8.8 & 26 & 2.6 & 887 & 88.6 \\
\hline $\begin{array}{l}\text { 7. A nurse may be obligated to participate in the euthanasia process due to his or } \\
\text { her profession. }\end{array}$ & 571 & 56.9 & 102 & 10.2 & 330 & 32.9 \\
\hline $\begin{array}{l}\text { 8. As a nurse, I would be prepared to participate in the euthanasia process if it were } \\
\text { legal. }\end{array}$ & 157 & 15.7 & 97 & 9.7 & 749 & 74.7 \\
\hline
\end{tabular}

cohabiting nurses agreed less than other respondents with the statement indicating that nurses should be present during the euthanasia procedure if this is what the patient wishes. They were also prone to agree less with the possible obligation of nurses to participate in euthanasia process than the participants who were not married or cohabiting (Table 4). The latter were also more prepared to participate in the euthanasia process if it were legal.

Nurses without children agreed more with the handling of euthanatics, insertion of I.V. cannula and preparing the patient for the euthanasia procedure than did those participants who had children (Table 4). Participants who had no children also agreed more often with the possible obligation of nurses to participate in the euthanasia process if it were legal (Table 4). Moreover, nurses without children were more prepared to participate in the possible euthanasia process than those who had children.

Having more recent, at least bachelor-level education indicated greater agreement with the handling of euthanatics, insertion of I.V. cannula and preparing the patient for the euthanasia procedure. Less educated nurses also disagreed more with the presence of nurses during euthanasia based on the wish of the patient as well as their preparedness to participate in the euthanasia process if it were legal than the participants with a higher level of education (Table 4).

Being religious had a negative influence on the nurses' attitudes towards their role in the euthanasia process. Non-religious nurses agreed more with the nurses' active involvement in the euthanasia-related decision-making than did their religious participants. The latter also indicated lower agreement with the handling of euthanatics or insertion of I.V. cannula as part of the euthanasia process compared with the non-religious nurses. Moreover, non-religious participants agreed more with nurses' presence and their possible obligation to the participation in the euthanasia process based on their profession (Table 4). The non-religious nurses were also more prepared to participate in the possible euthanasia process than the religious ones.

Nurses with greater work experience were less willing to actively participate in the decision-making process concerning euthanasia than nurses with shorter work experience (Table 4). Greater work experience also negatively influenced the nurses' agreement with the handling of euthanatics, insertion of I.V. cannula and preparing the patient for the euthanasia procedure. Furthermore, more experienced nurses reported less 


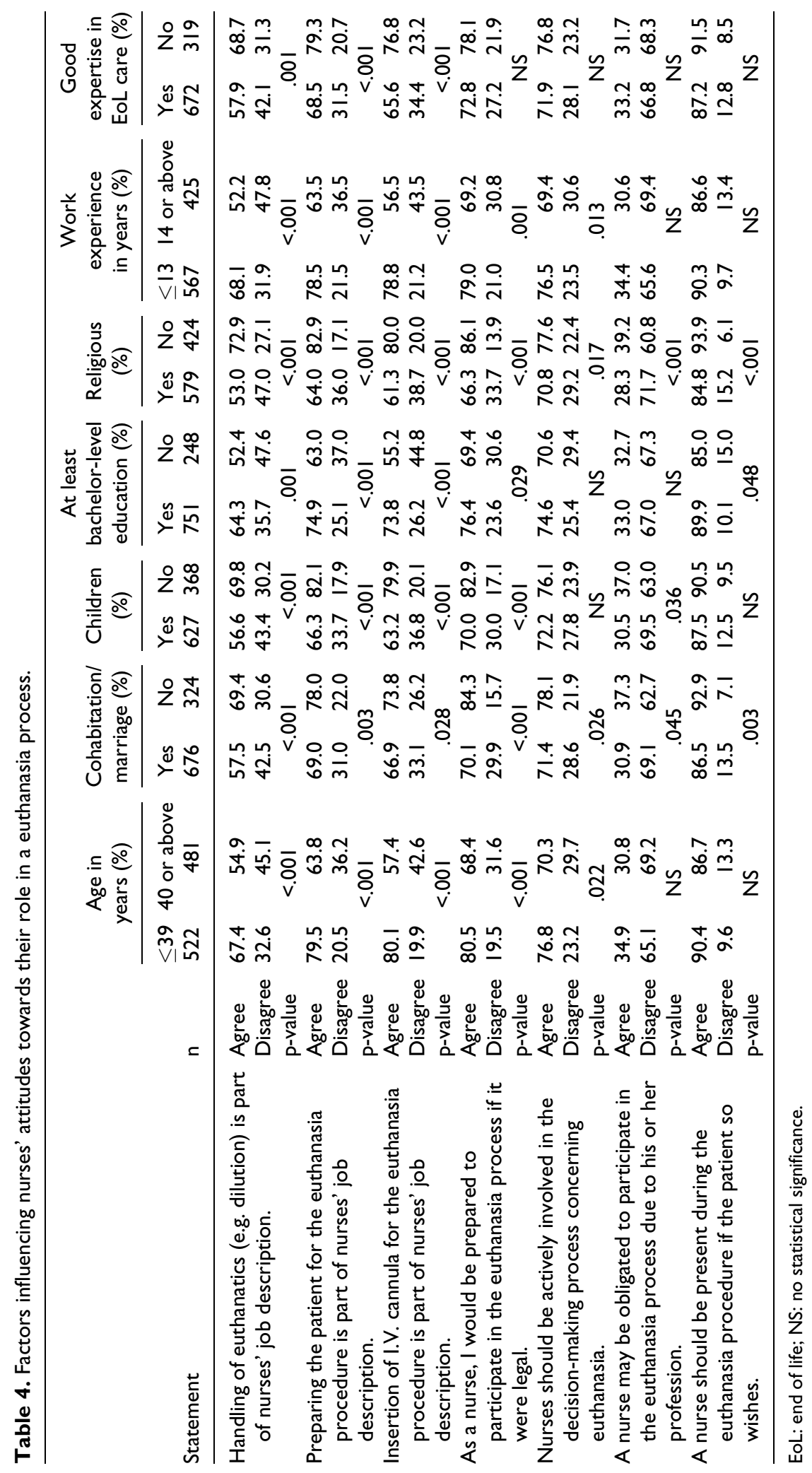


Table 5. Correlations between nurses' attitudes towards their role in a euthanasia process and euthanasia.

\begin{tabular}{|c|c|c|c|c|c|c|}
\hline \multirow[b]{2}{*}{ Statement } & \multicolumn{2}{|c|}{$\begin{array}{l}\text { Acceptance } \\
\text { of euthanasia }\end{array}$} & \multicolumn{2}{|c|}{$\begin{array}{l}\text { Legalisation } \\
\text { of euthanasia }\end{array}$} & \multicolumn{2}{|c|}{$\begin{array}{l}\text { Euthanasia-related } \\
\text { communication }\end{array}$} \\
\hline & $r$ & $\mathrm{P}$ & $r$ & $\mathrm{P}$ & $r$ & $\mathrm{P}$ \\
\hline $\begin{array}{l}\text { Nurses should be actively involved in the decision-making process } \\
\text { concerning euthanasia. }\end{array}$ & .282 & $<.001$ & .297 & $<.001$ & .168 & $<.001$ \\
\hline $\begin{array}{l}\text { Nurses' perspective should be taken into account in the decision- } \\
\text { making process concerning euthanasia. }\end{array}$ & .254 & $<.001$ & .240 & $<.001$ & .050 & .113 \\
\hline $\begin{array}{l}\text { Handling of euthanatics (e.g. dilution) is part of nurses' job } \\
\text { description. }\end{array}$ & .466 & $<.001$ & .425 & $<.001$ & .193 & $<.001$ \\
\hline $\begin{array}{l}\text { Preparing the patient for the euthanasia procedure is part of nurses' } \\
\text { job description. }\end{array}$ & .590 & $<.001$ & .534 & $<.001$ & .225 & $<.001$ \\
\hline $\begin{array}{l}\text { Insertion of I.V. cannula for the euthanasia procedure is part of } \\
\text { nurses' job description. }\end{array}$ & .513 & $<.001$ & .456 & $<.001$ & .179 & $<.001$ \\
\hline $\begin{array}{l}\text { A nurse should be present during the euthanasia procedure if the } \\
\text { patient so wishes. }\end{array}$ & .564 & $<.001$ & .472 & $<.001$ & .128 & $<.001$ \\
\hline $\begin{array}{l}\text { A nurse may be obligated to participate in the euthanasia process due } \\
\text { to his or her profession. }\end{array}$ & .261 & $<.001$ & .235 & $<.001$ & .163 & $<.001$ \\
\hline $\begin{array}{l}\text { As a nurse, I would be prepared to participate in the euthanasia } \\
\text { process if it were legal. }\end{array}$ & .740 & $<.001$ & .655 & $<.001$ & .290 & $<.001$ \\
\hline
\end{tabular}

preparedness to participate in the euthanasia process if it were legal compared with the inexperienced participants (Table 4).

Nurses who assessed their expertise in EoL care as good reported lower agreement with handling euthanatics, insertion of I.V. cannula and preparing the patient for the euthanasia procedure compared to other participant groups (Table 4).

\section{Connections between nurses' attitudes towards euthanasia and their role in euthanasia process}

A strong correlation (.740) was found between nurses' preparedness to participate in the euthanasia process and their acceptance of euthanasia (Table 5). Further connection was found between nurses' preparedness to participate and their attitude towards the legalisation of euthanasia (.655). Participants' agreement with the handling of euthanatics, preparing the patient for the euthanasia procedure and insertion of I.V. cannula correlated with their acceptance (.466-.590) and attitudes towards the legalisation (.425-.534) of euthanasia (Table 5). A further correlation was found between agreement on the presence of nurses during the euthanasia procedure based on the wish of the patient and the participant's acceptance (.564) and attitude towards the legalisation (.472) of euthanasia. By contrast, no strong correlation was found between nurses' attitudes towards their role in the euthanasia process and euthanasia-related communication (Table 5).

\section{Discussion}

For the first time, the results of this study represent nurses' attitudes towards their role in the euthanasia process in Finland. Our results contribute to the limited knowledge about nurses' attitudes towards their involvement in euthanasia and provide insight from a country where euthanasia is not legal.

The great majority of the participating nurses considered that the perspective of nurses should be taken into account in the decision-making concerning euthanasia. The number of participants who 
believed that nurses should be actively involved in the euthanasia-related decision-making was slightly smaller. These results support previous findings suggesting that nurses want to participate in the decision-making process concerning euthanasia. ${ }^{4,7,8,16}$ Furthermore, the results of our study in this regard are consistent with previous literature that emphasises nurses' involvement in euthanasiarelated decision-making. ${ }^{4,7,9,12,19}$ It is, however, noteworthy that the participants disagreed more with the active participation of nurses than the consideration of nurses' perspectives in decision-making. This may indicate that nurses are less willing to share the responsibility for the decision itself than to contribute to the discussion regarding a patient's euthanasia request. Although nurses' attitudes towards their involvement in the decision-making concerning euthanasia are only weakly connected to their attitudes towards euthanasia, it is noteworthy that younger nurses agreed more with the active participation compared with their older colleagues. One possible explanation for this is the more liberal environment in which the younger nurses have grown up. Previous literature has connected the acceptance of euthanasia with society's tolerance of personal freedom in life choices. ${ }^{37}$ However, further research is needed in order to address these differences.

The current results further demonstrate that the majority of the nurses agreed with some of the preparatory tasks, for example, the handling of euthanatics, insertion of I.V. cannula or preparing the patient for the euthanasia procedure, as part of their job description. This finding is supported by previous literature, which describes nurses' involvement in the preparation of euthanasia from both medical and contextual viewpoints ${ }^{7,20}$ However, it does not confirm other findings that indicate that nurses' primary tasks in the euthanasia process include the supportive care of the patient and his or her relatives. ${ }^{7,8,13,19}$ In the current results, nurses' expertise in EoL care negatively influenced their agreement with the tasks preparing the patient for euthanasia. This can be interpreted to be in line with previous literature, which suggests that nurses in palliative care more strongly disapprove euthanasia than nurses in other nursing areas. ${ }^{27}$ One possible explanation for this finding is the believe that euthanasia conflicts with the principles of palliative care. ${ }^{19}$ This aspect was not included in this study, and more research is needed in this regard. However, experienced nurses, as well as those who assess their expertise in EoL care as good, have most likely encountered euthanasia requests and other death-related themes in their work, which may have influenced their attitudes. The strong agreement may also have a pragmatic basis, as nurses may be more experienced in performing certain tasks (e.g. inserting an I.V. cannula) than physicians, as also described in previous literature. ${ }^{13}$ However, euthanasia should always be performed by an experienced physician who has the possibility to consult a senior colleague if needed and not shift the task to nurses.

In our results, nurses' attitudes towards the preparatory tasks as part of their job description were further connected with their attitudes towards euthanasia and its legalisation. As reported previously in Finland, nurses' attitudes towards euthanasia and its legalisation are supportive; nevertheless, the traditional, demographic characteristics fail to explain these attitudes. ${ }^{14}$ Current results highlight the need for further characterisation of the factors that influence nurses' attitudes towards their role in the euthanasia process. Deeper understanding about the complex phenomenon may be achieved by placing the patient-related characteristics and ethical aspects of euthanasia in the centre of future research. In addition, employment of qualitative and quantitative methods is recommended due to the distinct aspects of reality that they reflect and reveal. ${ }^{38}$

Participants in this study agreed strongly with having nurses present during the euthanasia procedure if this was based on the wish of the patient. This may be interpreted as the willingness to set one's personal views aside in order to fulfil the patient's needs, as also suggested in the literature. ${ }^{19}$

Despite the fact that the majority of the participating nurses disagreed with the obligation of nurses to participate in the euthanasia process based on their profession, one-third held it possible. This may be attributed to the fact that nurses lack the right to conscientious objection in Finland. For example, the National Advisory Board on Social Welfare and Health Care Ethics (ETENE) sees no grounds for granting healthcare professionals the subjective right to refuse assistance in abortion, ${ }^{39}$ which is a commonly used 
example in the discussion about conscientious objection. Therefore, some of the nurses may also consider the obligation based on their profession similarly in the case of euthanasia. This may be seen in line with the conventional incompatibilistic approach to conscientious objection, according to which conscientious objection is a personal preference that has no place in professional healthcare practices. ${ }^{40}$ However, it must be noted that this approach is neither the only nor the dominant approach towards conscientious objection. ${ }^{40}$

In a previous study, nurses regarded such obligation and involuntary participation in a euthanasia process as traumatising. ${ }^{24}$ Moreover, nurses regarded their right to conscientious objection, similarly, for example, in Belgium, Luxembourg and the Netherlands, ${ }^{1,13}$ as one of the most important prerequisites for the possible legalisation of euthanasia. ${ }^{24}$ The healthcare professionals' right to refuse their participation is further emphasised by the IAHPC ${ }^{25}$ as well as the valid euthanasia laws. ${ }^{1}$

In this study, the majority of the nurses would be prepared to participate in the euthanasia process if it were legal. The agreement correlated strongly with the nurses' attitudes towards euthanasia and its legalisation. It does not, however, confirm previous literature, which points out that a philosophical agreement with euthanasia differs from the willingness to be actively involved in it. ${ }^{20}$ Despite the strong agreement with involvement in a euthanasia process, attention should particularly be paid to the nurses who disagree with participating in the euthanasia process. Involuntary participation in the euthanasia process may cause serious conflicts related to the nurse's personal values or philosophy of life. Moreover, it may lead to a situation where continuing in the nursing profession could be impossible, resulting in increased career changes. ${ }^{13,24}$ In addition, the refusal to participate may cause conflicts within the caring team and carries a risk that the nurses who decide not to participate in the euthanasia process are labelled or bullied. Therefore, the application of specific safety and support mechanisms (e.g. institutional ethics policies, supervision of work and education of nurse leaders) should be considered to protect nurses from harm, especially in countries where nurses lack the right to conscientious objection. ${ }^{41}$

\section{Limitations}

Despite the strong evidence and varied results, this study has some limitations. The used recruitment strategy resulted in a large and heterogenous sample. However, due to the fact that data were collected online, nurses without an Internet connection or computer were excluded, as is the case with all webbased surveys. ${ }^{31,32}$ The sample was compared with the data of a previous study, which derived the random sample from the register of the Finnish Nursing Association. ${ }^{42}$ Based on the comparison, these two datasets did not differ from each other regarding gender distribution or the mean age of the participants. This may be considered to strengthen the generalisability of the results as well of the recruitment strategy used in this study. The used questionnaire was tested for its validity and reliability prior to the data collection. However, it is worth mentioning that the nurses were asked to state their latest, and not the highest, level of education, which might have affected the assessment of the association between the nurses' attitudes towards their role in the euthanasia process and their level of education. Moreover, the nurses were not asked to disclose whether they were personally prepared to carry out euthanasia if it were legal. This question was excluded to avoid the risk of attracting answers based on what is socially acceptable due to the illegal status of euthanasia in Finland. Despite these limitations, the used questionnaire captured nurses' attitudes towards their role in the euthanasia process comprehensively and from different perspectives, and presented novel knowledge.

\section{Conclusion}

This article contributes to the ongoing debate on euthanasia by revealing nurses' attitudes towards their role in the euthanasia process from different perspectives. The results give rare insight into nurses' attitudes in a 
society where euthanasia is currently illegal, providing new knowledge that can be utilised in euthanasiarelated discussions in different contexts.

Nurses are willing to be involved in the decision-making process concerning euthanasia; however, they agree more with acting in the role of a consultant than an active participant in the decision itself. They also agree with the preparatory tasks related to euthanasia and their presence in the euthanasia procedure, but disagree with the possible obligation to be involved in it because of their profession. Due to the potential harm arising from involuntary participation in a euthanasia process, special attention must be paid on the nurses, who refuse to be involved.

\section{Acknowledgements}

The authors would like to express their gratitude to all the nurses, who participated in this study, without whom this article would not exist.

\section{Conflict of interest}

The author(s) declared no potential conflicts of interest with respect to the research, authorship and/or publication of this article.

\section{Funding}

The author(s) disclosed receipt of the following financial support for the research, authorship, and/or publication of this article: This research was supported by the doctoral programme of the University of Eastern Finland. The funder had no role in study design, data collection and analysis; the decision to publish; or the preparation of the manuscript.

\section{References}

1. Nys H. A discussion of the legal rules on euthanasia in Belgium briefly compared with the rules in Luxembourg and the Netherlands. In: Jones D, Gastmans C and MacKellar C (eds) Euthanasia and assisted suicide: lessons from Belgium. Cambridge: Cambridge University Press, (In Press).

2. Emanuel E, Onwuteaka-Philipsen B, Urwin J, et al. Attitudes and practices of euthanasia and physician-assisted suicide in the United States, Canada, and Europe. JAMA 2016; 316(1): 79-90.

3. The House of Commons. BILL C-14. 2016, http://www.parl.gc.ca/HousePublications/Publication.aspx? Language $=E \&$ Mode $=1 \&$ DocId $=8309978($ accessed 24 May 2017).

4. Elmore J, Wright DK and Paradis M. Nurses' moral experiences of assisted death. Nurs Ethics. Epub ahead of print 1 January 2016. DOI: 10.1177/0969733016679468.

5. Seppänen E, Viinanen I, Soininvaara O, et al. Eutanasia-aloite hyvän kuoleman puolesta. 2016, https://www.kan salaisaloite.fi/fi/aloite/2212 (accessed 24 May 2017).

6. Kansalaisaloite.fi. Citizens' initiatives in Finland. 2016, https://www.kansalaisaloite.fi/fi/ohjeet/briefly-in-english (accessed 24 May 2017).

7. Dierckx de Casterlé B, Denier Y, De Bal N, et al. Nursing care for patients requesting euthanasia in general hospitals in Flanders, Belgium. $J$ Adv Nurs 2010; 66(11): 2410-2420.

8. Francke AL, Albers G, Bilsen J, et al. Nursing staff and euthanasia in the Netherlands. A nation-wide survey on attitudes and involvement in decision making and the performance of euthanasia. Patient Educ Couns 2016; 99 : 783-789.

9. Van Bruchem-Van De Scheur GG, Van Der Arend, Huijer Abu-Saad H, et al. The role of nurses in euthanasia and physician-assisted suicide in The Netherlands. J Med Ethics 2008; 34(4): 254-258.

10. Denier Y, Gastmans C, De Bal N, et al. Communication in nursing care for patients requesting euthanasia: a qualitative study. J Clin Nurs 2010; 19(23-24): 3372-3380. 
11. Van Bruchem-Van De Scheur GG, Van Der Arend AJ, Huijer Abu-Saad H, et al. Euthanasia and assisted suicide in Dutch hospitals: the role of nurses. J Clin Nurs 2008; 17(12): 1618-1626.

12. Bilsen J, Robijn L, Chambaere K, et al. Nurses' involvement in physician-assisted dying under the euthanasia law in Belgium. Int J Nurs Stud 2014; 51(12): 1696-1697.

13. Van Bruchem-Van De Scheur A, Van der Arend A, Van Wijmen F, et al. Dutch nurses' attitudes towards euthanasia and physician-assisted suicide. Nurs Ethics 2008; 15(2): 186-198.

14. Terkamo-Moisio A, Kvist T, Kangasniemi M, et al. Nurses' attitudes towards euthanasia in conflict with professional ethical guidelines. Nurs Ethics 2017; 24(1): 70-86.

15. Vézina-Im L, Lavoie M, Krol P, et al. Motivations of physicians and nurses to practice voluntary euthanasia: a systematic review. BMC Palliat Care 2014; 13(1): 20.

16. Kranidiotis G, Ropa J, Mprianas J, et al. Attitudes towards euthanasia among Greek intensive care unit physicians and nurses. Heart Lung 2015; 44(3): 260-263.

17. Naseh L, Rafiei H and Heidari M. Nurses' attitudes towards euthanasia: a cross-sectional study in Iran. Int J Palliat Nurs 2015; 21(1): 43-48.

18. Tamayo-Velazquez MI, Simon-Lorda P and Cruz-Piqueras M. Euthanasia and physician-assisted suicide: knowledge, attitudes and experiences of nurses in Andalusia (Spain). Nurs Ethics 2012; 19(5): 677-691.

19. De Bal N, Gastmans C and Dierckx de Casterlè B. Nurses' involvement in the care of patients requesting euthanasia: a review of the literature. Int J Nurs Stud 2008; 45(4): 626-644.

20. Verpoort C, Gastmans C, De Bal N, et al. Nurses' attitudes to euthanasia: a review of the literature. Nurs Ethics 2004; 11(4): 347-365.

21. Asai A, Ohnishi M, Nagata SK, et al. Doctors' and nurses' attitudes towards and experiences of voluntary euthanasia: survey of members of the Japanese Association of Palliative Medicine. J Med Ethics 2001; 27(5): 324-330.

22. Karadeniz G, Yanikkerem E, Pirincci E, et al. Turkish health professional's attitude toward euthanasia. Omega (Westport) 2008; 57(1): 93-112.

23. Turla A, Özkara E, Özkanli Ç, et al. Health Professionals' Attitude Toward Euthanasia: a Cross-Sectional Study from Turkey. Omega (Westport) 2006; 54(2): 135-145.

24. Terkamo-Moisio A, Kvist T and Pietilä A. Multifaceted nature of euthanasia: perceptions of Finnish registered nurses. J Hosp Palliat Nurs 2015; 17(2): 105-112.

25. De Lima L, Woodruff R, Pettus K, et al. International Association for Hospice and Palliative Care Position Statement: euthanasia and physician-assisted suicide. J Palliat Med 2017; 20(1): 8-14.

26. Huber S and Huber OW. The Centrality of Religiosity Scale (CRS). Religions 2012; 3(3): 710.

27. Holt J. Nurses' attitudes to euthanasia: the influence of empirical studies and methodological concerns on nursing practice. Nurs Philos 2008; 9(4): 257-272.

28. Louhiala P, Enkovaara H, Halila H, et al. Finnish physicians' attitudes towards active euthanasia have become more positive over the last 10 years. $J$ Med Ethics 2015; 41(4): 353-355.

29. Ailasmaa R. Health care and social welfare personnel 2011. Official Statistics of Finland. Helsinki: National Institute for Health and Welfare, 2014.

30. The Finnish Nurses Association. I can I know I care. 2014, http://www.nurses.fi/@Bin/201545/SHL_ESITE_ ENG_auk.pdf (Accessed 24 May 2017).

31. Otieno DO and Matoke VB. Social Media as tool for conducting academic research. Int J Adv Res Comput Sci Software Eng 2014; 4(1): 962-967.

32. Khatri C, Chapman SJ, Glasbey J, et al. Social media and internet driven study recruitment: evaluating a new model for promoting collaborator engagement and participation. PLOS ONE 2015; 10(3): e0118899.

33. Gosling SD and Mason W. Internet research in psychology. Annu Rev Psychol 2015; 66: 877-902.

34. TENK. Ethical principles of research in the humanities and social and behavioural sciences and proposals for ethical review, 2009, http://www.tenk.fi/sites/tenk.fi/files/ethicalprinciples.pdf 
35. Markham A and Buchanan E. Ethical decision-making and Internet research: recommendations from the AoIR Ethics Working Committee (Version 2.0), 2012, http://ethics.iit.edu/ecodes/sites/default/files/ethics2.pdf

36. Field A. Discovering statistics using IBM SPSS statistics. 4th ed. London: Sage, 2013.

37. Cohen J, Van Landeghem P, Carpentier N, et al. Different trends in euthanasia acceptance across Europe. A study of 13 western and 10 central and eastern European countries, 1981-2008. Eur J Public Health 2013; 23(3): 378-380.

38. Dierckx de Casterle B, Grypdonck M, Cannaerts N, et al. Empirical ethics in action: lessons from two empirical studies in nursing ethics. Med Health Care Philos 2004; 7(1): 31-39.

39. The National Advisory Board on Social Welfare and Health Care Ethics ETENE. Right of a health care professional to refuse to perform an abortion, 2013, http://etene.fi/documents/1429646/1561478/2013 + Right + of $+\mathrm{a}+$ health + care + professional + to+refuse+to+perform + an + abortion.pdf/b8305068-d890-491e89ea-25c3ef412135 (accessed 24 May 2017).

40. Wernow JR and Gastmans C. A review and taxonomy of argument-based ethics literature regarding conscientious objections to end-of-life procedures. Christ Bioet 2010; 16(3): 274.

41. Lemiengre J, Gastmans $C$, Schotsmans $P$, et al. Impact of written ethics policy on euthanasia from the perspective of physicians and nurses: a multiple case study in hospitals. AJOB Prim Res 2010; 1(2): 49-60.

42. Ryynänen $\mathrm{O}$, Myllykangas M, Viren $\mathrm{M}$, et al. Attitudes towards euthanasia among physicians, nurses and the general public in Finland. Public Health 2002; 116(6): 322-331. 